\title{
Studi Mengenai Karakteristik Pagar Berdasarkan Klasifikasi Tipe Rumah Tinggal
}

\author{
Ratih Dian Saraswati \\ Universitas Katolik Soegijapranata Semarang \\ email: rd_saraswati@unika.ac.id \\ Salma Azhar \\ Universitas Katolik Soegijapranata Semarang \\ email: salmaazhar14@yahoo.com
}

\begin{abstract}
The fence of a dwelling house was originally as a barrier between the property area and the surrounding environment. In a residential house, the fence also acts as a boundary between one house and another. In development, the fence of a residential house becomes part of the design of a residential house. Fences become a very important element in a dwelling, so the fence design becomes an identity of the occupants of the dwelling. How the social strata of residents can affect the appearance and physical condition of a residential fence. The study was conducted in several residential houses with various types of residential classification in Pasadena Housing Semarang. The results showed that the material of a fence turned out to be influenced by the level of social strata of residential owners as seen from the classification of the type of residence.
\end{abstract}

Keywords: fence, residential house, social strata

\begin{abstract}
Abstrak
Pagar sebuah rumah tinggal pada awalnya sebagai pembatas antara area properti dan lingkungan sekitar. Pada sebuah rumah tinggal, pagar juga berperan sebagai batas antara rumah tinggal satu dengan yang lain. Pada perkembangan, pagar sebuah rumah tinggal menjadi bagian dari desain sebuah rumah tinggal. Pagar menjadi elemen yang sangat penting pada sebuah rumah tinggal, sehingga desain pagar menjadi sebuah identitas dari penghuni rumah tinggal tersebut. Bagaimana strata sosial penghuni rumah tinggal dapat mempengaruhi tampilan dan kondisi fisik sebuah pagar rumah tinggal. Penelitian dilakukan pada beberapa rumah tinggal dengan berbagai klasifikasi tipe rumah tinggal di Perumahan Pasadena Semarang. Hasil penelitian didapatkan bahwa material sebuah pagar ternyata mendapat pengaruh dari tingkat strata sosial pemilik rumah tinggal yang dilihat dari klasifikasi tipe rumah tinggal tersebut.
\end{abstract}

Kata kunci: pagar, rumah tinggal, strata sosial

\section{PENDAHULUAN}

Pagar, menurut Kamus Besar

Bahasa Indonesia (KBBI), ialah sesuatu yang digunakan untuk membatasi (mengelilingi, menyekat) pekarangan, tanah, rumah, kebun, dan sebagainya. Pada awalnya sebuah pagar adalah sebagai pembatas area teritori seseorang atau wilayah. Namun semakin berkembang ilmu desain dan kesan orang terhadap 
sebuah nilai estetika atau keindahan, desain sebuah pagar rumah tinggal menjadi berkembang dan diperhitungkan.

Desain sebuah pagar rumah tinggal menjadi cerminan dari pemilik rumah tinggal tersebut. Fasad depan sebuah rumah tinggal digambarkan paling utama adalah sebuah pagar. Cerminan strata sosial pemilik sebuah rumah tinggal mempengaruhi desain material pagar rumah tinggalnya.

\section{LANDASAN TEORI}

\section{Pagar Rumah}

Menurut Imelda Akmal (2017), pagar sebagai bagian dari keseluruhan rumah tinggal memiliki fungsi sendiri. Adapun beberapa aspek fungsi tersebut adalah sebagai berikut:

\section{Pagar sebagai Batas Properti}

Ada baiknya setiap lahan pekarangan yang menjadi teritori seseorang diberi penanda agar tidak terjadi kekeliruan atau kesalahpahaman batas area kepemilikan. Pada masa lalu, masyarakat berinisiatif memberi garis pembatas area kepemilikan lahan dengan cara mengaplikasikan material sederhana, yaitu dengan tali, kawat, batu, bamboo, atau sesuatu benda mengelilingi area teritori tersebut. (gambar 1)

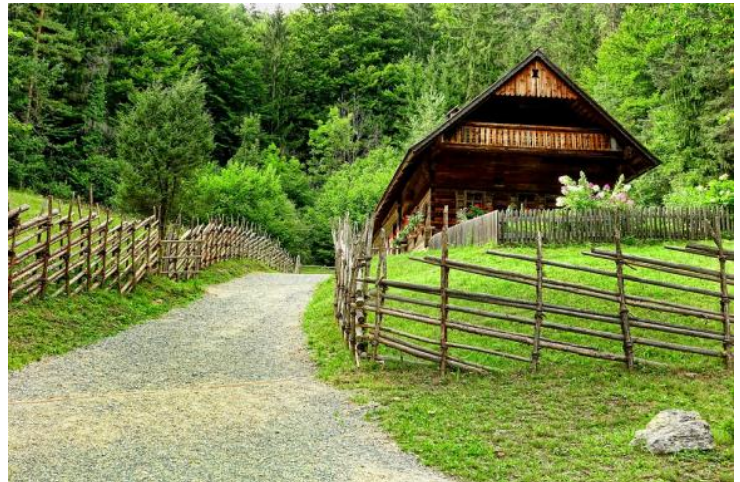

\section{Gambar 1}

Pagar Bambu sebagai Batas Teritori

Sumber: https://pixabay.com/id/photos/kayu-pagarpagar-kayu-3160743/

Saat ini, pagar sebagai batas properti masih dibuat dengan konsep yang sama, mengelilingi area sekitar properti. Bedanya, desain yang digunakan merupakan perpaduan antara desain dinding masif dan desain pagar yang sleek. Bagian samping bangunan dibuat dari konstruksi masif, beton atau campuran batu bata dan semen, sementara bagian main entrance dihiasi pagar yang pintunya mudah dibuka dan ditutup sebagai akses keluar masuk utama.

\section{Pagar sebagai Pengaman}

Selain berfungsi sebagai batas properti, kehadiran pagar juga melindungi atau mengamankan bangunan dari hal-hal yang tidak diinginkan, misalnya kehadiran taku tak diundang. Secara tidak langsung, keberadaan pagar mempersulit akses masuk ke dalam bangunan. Sebagai bagian terdepan, amat wajar jika pagar dilengkapi beragam fasilitas yang berfungsi 
melindungi pemilik dan keseluruhan property bangunan. Tempat berjaga, misalnya pos keamanan, berikut penjaganya hamper selalu ditempatkan berdekatan dengan pintu pagar. Bahkan tak jarang pintu pagar utama hunian yang relative besar diatur buka - tutupnya oleh petugas keamanan.

Melengkapi fungsi sebagai pelindung dan pengaman, sebaiknya pagar dibuat dengan konstruksi yang kokoh agar tidak mudah dibobol. Selain faktor konstruksi, agar fungsinya semakin optimal, jangan lupa melengkapi pintu pagar dengan fasilitas tambahan berupa kunci gembok, rantai atau gerendel.

Fungsi pagar yang terutama dan utama adalah untuk fungsi keamanan. Pagar yang dikatakan aman biasanya memiliki jarak antara teralis yang tidak terlalu lebar alias sempit, sehingga tidak bias ditembus dengan alasan apapun. Faktor ketinggian pun harus diperhatikan karena semakin tinggi pagarnya, maka semakin sulit pula untuk dipanjat.

\section{Pagar sebagai Elemen Estetika}

Pentingnya kesan pertama memang diakui oleh banyak orang. Setidaknya jargon "kesan pertama begitu menggoda" benar adanya. Layaknya manusia yang senang memperindah penampilan dari segi busana, aksesoris hingga tata rias, berbagai bagian bangunan juga perlu diperhatikan keindahan serta keapikannya. Pagar bukan perkecualian. Maka, jangan heran jika saat ini pagar bersolek sedemikian rupa sehingga tampilan makin memikat.

Terdapat beragam alternatif yang dapat diaplikasikan pada pagar oleh pemilik hunian agar pagar rumah tampil unik dan memiliki identitas. Kata kuncinya hanya satu yaitu jangan bosan bereksperimen dan bereksplorasi mencari material yang jarang dipakai sehingga pagar kian unik, khas dan yang tepenting mencerminkan karakter dari penghuni rumah tinggal tersebut.

Dalam sebuah karya arsitektur, nilai-nilai estetika dalam dilihat dalam komposisi bentuk yang meliputi:

1. Garis, tercipta dari sebuah titik yang tidak mempunyai dimensi, namun ketika titik itu bergerak satu posisi ke posisi yang lainnya, akan menjadi sebuah garis yang mempunyai dimensi. Garis hanya mempunyai satu dimensi yaitu panjang.

2. Bentuk, dasar abstrak mempunyai abstrak sebagai berikut: 
a. Persegi dan Kubus, merupakan bentuk sederhana yang statis, stabil dan kuat profil sudutnya.

b. Segitiga dan Piramida, bentuk ini akan stabil apabila ditempatkan pada dasarnya, akan tetapi akan labil bila dibalik. Kedua bentuk ini kuat karena profil sudutnya.

c. Lingkaran dan Bola, bentuk ini dapat bersifat statis ataupun gerak. Apabila bentuk ini berdekatan dengan bentuk yang menyudut, maka akan condong bergerak melingkar. Akan tetapi bila dilihat tersendiri bentuk ini bersifat stabil dan memusat.

3. Tekstur adalah suatu bentuk pada permukaan yang dapat diketahui melalui indra peraba. Dengan menyentuh suatu permukaan, maka kita akan dapat mengetahui tekstur pada suatu objek. Tekstur juga dapat digunakan untuk menjelaskan karakteristik permukaan material seperti batu, kayu, dan kain.
4. Warna adalah salah satu elemen desain yang paling ekspresif karena kualitasnya mempengaruhi seseorang secara emosional. Dalam teori warna kita mengenal dua macam sistem yang digunakan dalam menyusun warna, yaitu:

a. Prang Colour System

b. Munsell Colour System

5. Skala adalah perbandingan antara sebuah benda/obyek dengan elemen tertentu. Skala dapat dibedakan menjadi:

a. Skala intim

b. Skala normal

c. Skala monumental

6. Organisasi estetika, menentukan ekspresi suatu bentuk. Sebagai elemen komposisi, organisasi bentuk meliputi:
a. Berbatasan
b. Repetisi
c. Overlapping
d. Irama

\section{Klasifikasi Tipe Rumah}

Menurut Suparno (2006), dalam perumahan, jenis rumah diklasifikasikan berdasarkan tiga tipe rumah. Jenis rumah tersebut terdiri atas: 
1. Rumah sederhana merupakan rumah bertipe kecil, yang mempunyai keterbatasan dalam perencanaan ruangnya. Rumah tipe ini sangat cocok untuk keluarga kecil dan masyarakat yang berdaya beli rendah. Pada umumnya, rumah sederhana mempunyai luas rumah $22 \mathrm{~m}^{2}$ $\mathrm{s} / \mathrm{d} 36 \mathrm{~m}^{2}$, dengan luas tanah $60 \mathrm{~m}^{2} \mathrm{~s} / \mathrm{d} 75 \mathrm{~m}^{2}$.

2. Rumah menengah merupakan rumah bertipe sedang. Pada tipe ini, cukup banyak kebutuhan ruang yang dapat direncanakan dan perencanaan ruangnya lebih leluasa dibanding pada rumah sederhana. Pada umumnya, rumah menengah ini mempunyai luas rumah $45 \mathrm{~m}^{2}$ s/d $120 \mathrm{~m}^{2}$, dengan luas tanah $80 \mathrm{~m}^{2} \mathrm{~s} / \mathrm{d} 200 \mathrm{~m}^{2}$.

3. Rumah mewah merupakan rumah bertipe besar, biasanya dimiliki oleh masyarakat berpenghasilan dan berdaya beli tinggi.

\section{METODE PENELITIAN}

Metode penelitian yang digunakan adalah metode kualitatif, deskriptif naratif untuk mengetahui dan menganalisis karakteristik pagar rumah yang dijadikan obyek pengamatan. Pengumpulan data dilakukan dengan cara melakukan pengamatan lapangan pada obyek terpilih. Pengamatan dan pengumpulan data tersebut dilakukan untuk mendapatkan gambaran dan data mengenai karateristik pagar berdasarkan tipe hunian yang berbeda.

Pengambilan data dengan pengumpulan data primer dan data sekunder, yaitu:

a. Data Primer merupakan data yang diperoleh secara langsung hunian rumah tinggal di Permukiman Pasadena relatif beragam, meliputi desain pagar, material pagar, dan dimensi atau ukuran pagar.

b. Data Sekunder merupakan data yang diperoleh melalui buku-buku dan jurnal yang berkaitan dengan topik penelitian, yaitu desain pagar. Setelah data primer dan sekunder didapatkan, lalu dilakukan analisis berdasarkan observasi/ pengamatan dengan mengunjungi lokasi Permukiman Pasadena Semarang. Permukiman Pasadena Semarang dijadikan obyek penelitian dikarenakan tipe rumah tinggal yang beragam. 


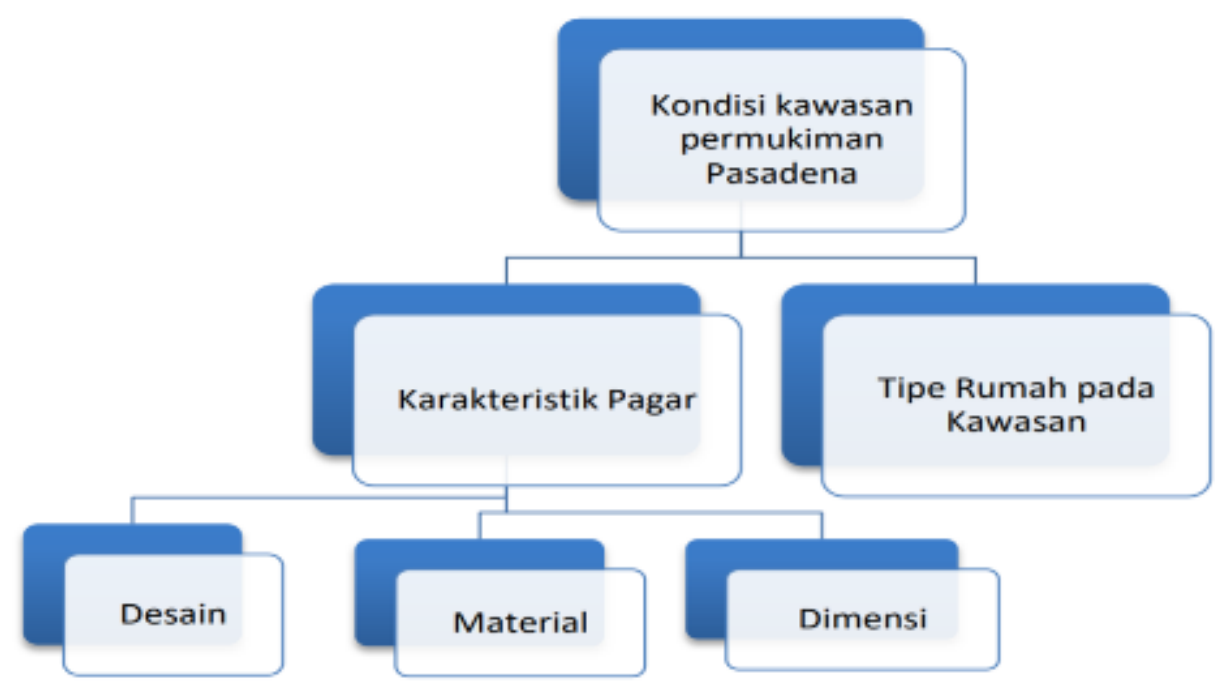

Gambar 2

Bagan Alur Pembahasan

Sumber: Analisa Pribadi

\section{PEMBAHASAN PENELITIAN}

\section{Batasan Lokasi}

Obyek pengamatan berada pada kawasan Perumahan Pasadena Semarang. Berlokasi di kota Semarang dengan luas 133.500 Ha yang termasuk dalam Kecamatan Ngaliyan dan berada pada kawasan BWK X. Sebagai Batasan, wilayah yang diambil sampel adalah beberpa rumah tinggal di Jalan Candi Kencana I, Jalan Candi Intan IV, dan Jalan Candi Intan III. (gambar 3)

\section{Sampel Penelitian}

Menurut Suparno (2006), dalam perumahan, jenis rumah diklasifikasikan berdasarkan tiga tipe rumah; rumah mewah, rumah menengah, dan rumah sederhana. Bedasarkan teori tersebut, beberapa sampel penelitian yang diambil pada kawasan Perumahan Pasadena Semarang berdasarkan tipe rumah.

Rumah tinggal yang berada di Jalan Candi Kencana I rata-rata memiliki luasan rumah yang besar dibanding pada rumah tinggal di jalan lain di dalam kawasan perumahan. Pada Jalan Candi Kencana I diambil tiga sampel rumah bertipe mewah. Pada Jalan Candi Intan IV, diambil rumahrumah tinggal bertipe menengah. Sedangkan pada Jalan Candi Intan III diambil tipe rumah tinggal dengan tipe sederhana. 


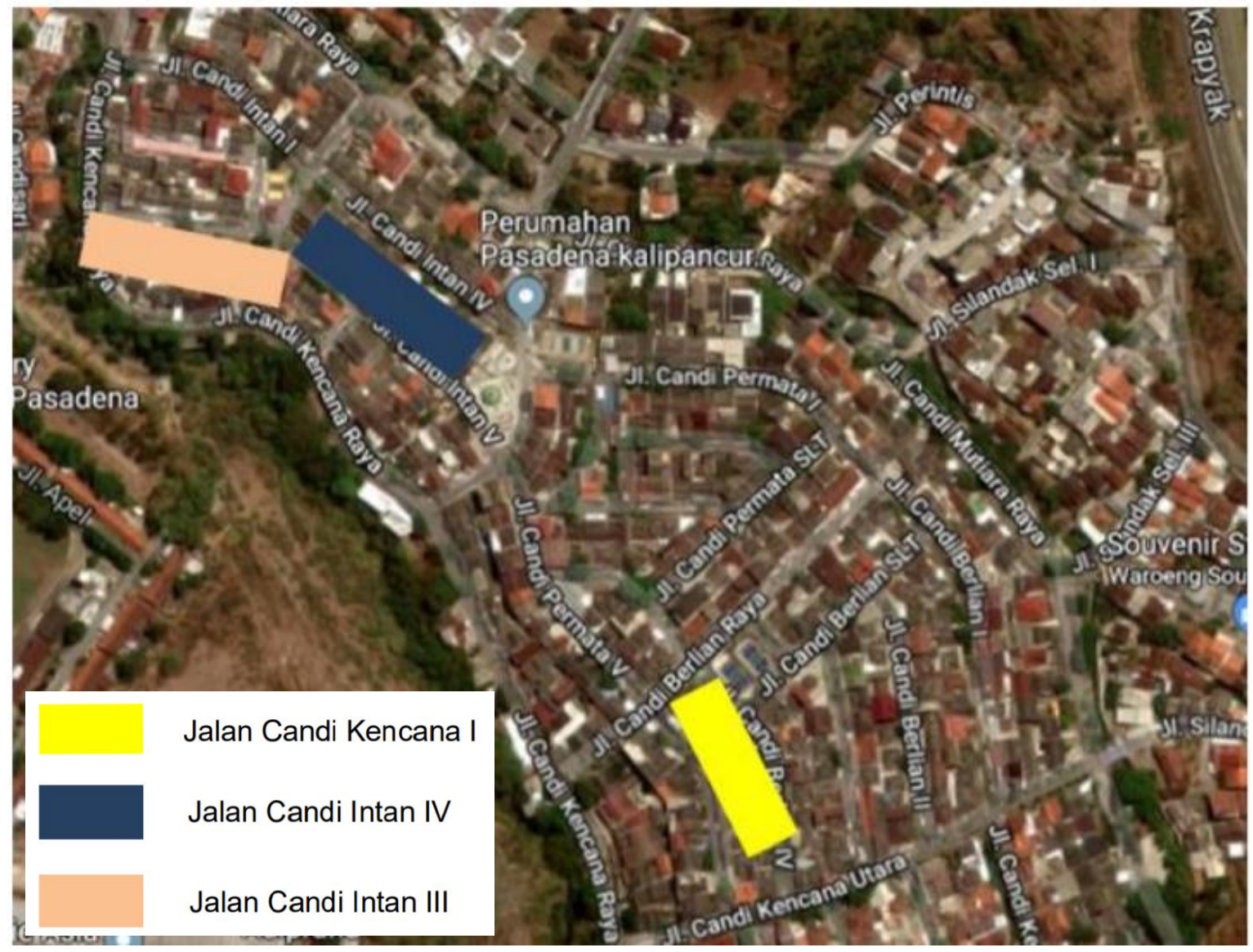

Gambar 3

Peta Batasan Penelitian pada Kawasan Perumahan Pasadena Semarang

Sumber: Analisa Pribadi

Rumah A di Jalan Candi Kencana I memiliki luasan 235,3 $\mathrm{m}^{2}$. Rumah B memiliki luasan 232,7 $\mathrm{m}^{2}$ dan rumah $\mathrm{C}$ memiliki luasan $417 \mathrm{~m}^{2}$. (gambar 4)

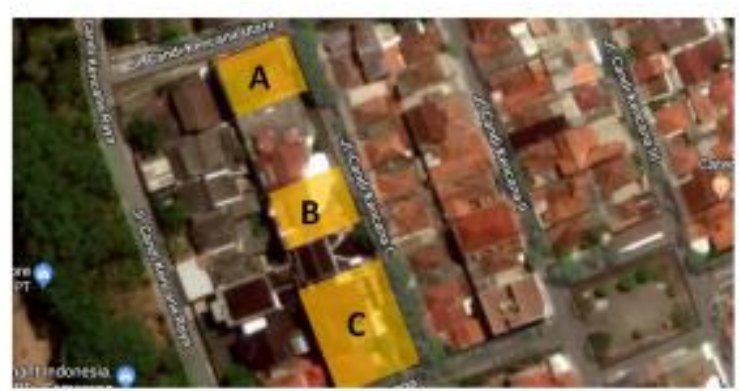

Gambar 4

Sampel Rumah di Jalan Candi Kencana I Sumber: Analisa Pribadi
Pada Jalan Candi Intan IV, diambil dua rumah sebagai sampel dengan tipe menengah dan sederhana. Rumah A memiliki luasan $141,8 \mathrm{~m}^{2}$ dan rumah $\mathrm{B}$ memiliki luasan $92,3 \mathrm{~m}^{2}$. (gambar 5)

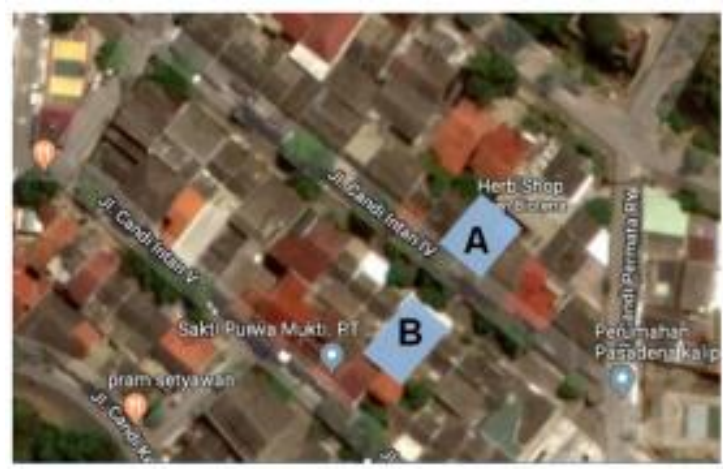




\section{Gambar 5 \\ Sampel Rumah di Jalan Candi Intan IV \\ Sumber: Analisa Pribadi}

Pada Jalan Candi Intan III, diambil

tiga rumah sebagai sampel dengan tipe

sederhana. Rumah A memiliki luasan $65,78 \mathrm{~m}^{2}$, rumah $\mathrm{B}$ memiliki luasan $61,48 \mathrm{~m}^{2}$, dan rumah $\mathrm{C}$ memiliki luasan $52,37 \mathrm{~m}^{2}$.

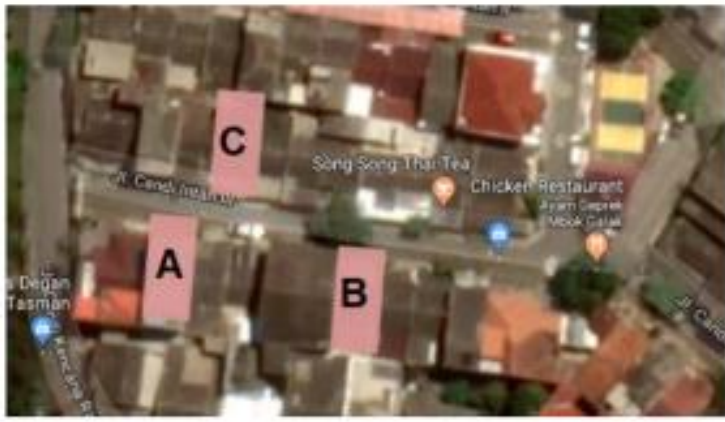

\section{Gambar 6}

Sampel Rumah di Jalan Candi Intan III Sumber: Analisa Pribadi

\section{PEMBAHASAN PENELITIAN}

Tabel 1

Hasil Penelitian Sampel Rumah Tinggal

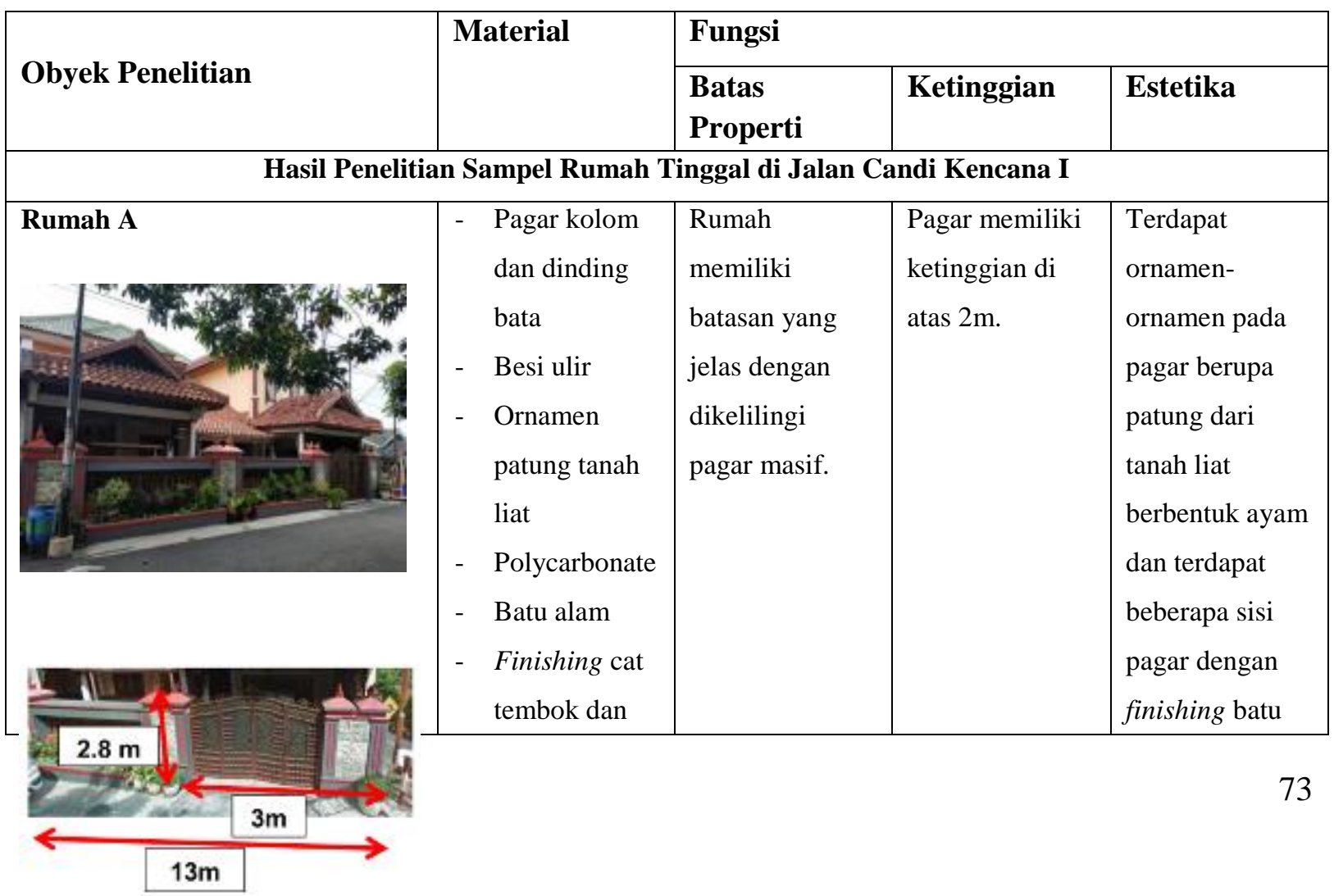




\begin{tabular}{|c|c|c|c|c|}
\hline $\begin{array}{l}\text { Rumah A memiliki luas } 235,3 \mathrm{~m}^{2} \text {. } \\
\text { Termasuk kategori rumah mewah } \\
\text { dikarenakan memiliki luasan lebih } \\
\text { dari } 200 \mathrm{~m}^{2}\end{array}$ & besi & & & alam. \\
\hline $\begin{array}{l}\stackrel{12,2 \mathrm{~m}}{\longrightarrow} \\
\text { Rumah B memiliki luas } 232,7 \mathrm{~m}^{2} \text {. } \\
\text { Termasuk kategori rumah mewah } \\
\text { dikarenakan memiliki luasan lebih } \\
\text { dari } 200 \mathrm{~m}^{2}\end{array}$ & $\begin{array}{l}\text { - Pagar kolom } \\
\text { dan dinding } \\
\text { bata } \\
\text { - Pagar } \\
\text { alumunium } \\
\text { - Batu alam } \\
\text { - Finishing cat } \\
\text { tembok dan } \\
\text { besi }\end{array}$ & $\begin{array}{l}\text { Memiliki } \\
\text { Batasan lahan } \\
\text { yang jelas } \\
\text { berupa } \\
\text { perpaduan } \\
\text { pagar dinding } \\
\text { masif dan pagar } \\
\text { alumunium. }\end{array}$ & $\begin{array}{l}\text { Pagar memiliki } \\
\text { ketinggian di } \\
\text { atas } 1 \mathrm{~m} .\end{array}$ & $\begin{array}{l}\text { Desain pagar } \\
\text { tidak hanya } \\
\text { sebagai batas } \\
\text { dan keamanan } \\
\text { tapi memiliki } \\
\text { elemen estetika } \\
\text { dengan adanya } \\
\text { pengaplikasian } \\
\text { batu alam pada } \\
\text { beberapa sisi. }\end{array}$ \\
\hline $\begin{array}{l}\text { Rumah C memiliki luasan } 417 \mathrm{~m}^{2} \text {. } \\
\text { dikategorikan sebagai rumah } \\
\text { mewah dikarenakan memiliki } \\
\text { luasan lebih dari } 200 \mathrm{~m}^{2} \text {. }\end{array}$ & $\begin{array}{l}\text { - Pagar kolom } \\
\text { dan dinding } \\
\text { batu bata } \\
\text { - } \text { Besi hollow } \\
\text { - Pintu kayu } \\
\text { - } \text { batu alam } \\
\text { - } \text { finishing cat } \\
\text { tembok dan } \\
\text { besi }\end{array}$ & $\begin{array}{l}\text { Rumah } \\
\text { dikelilingi } \\
\text { batasan yang } \\
\text { jelas pagar } \\
\text { dinding masif } \\
\text { dan pagar besi. }\end{array}$ & $\begin{array}{l}\text { Pagar memiliki } \\
\text { ketinggian lebih } \\
\text { dari } 2 \mathrm{~m} \text {. }\end{array}$ & $\begin{array}{l}\text { Desain pagar } \\
\text { selaras dengan } \\
\text { rumah yang } \\
\text { modern } \\
\text { minimalis. } \\
\text { Terdapat dua } \\
\text { akses masuk, } \\
\text { akses pertama } \\
\text { untuk akses } \\
\text { pejalan kaki } \\
\text { berupa gate } \\
\text { dengan batu } \\
\text { alam dan pintu } \\
\text { kayu. Untuk } \\
\text { akses kedua } \\
\text { sebagai akses }\end{array}$ \\
\hline
\end{tabular}


Jurnal PRAXIS | Vol. 2 | No. 1 | September 2019

\begin{tabular}{|c|c|c|c|c|}
\hline & & & & mobil. \\
\hline \multicolumn{5}{|c|}{ Hasil Penelitian Sampel Rumah Tinggal di Jalan Candi Intan III } \\
\hline $\begin{array}{l}\stackrel{1 \mathrm{~m}}{\leftarrow} \underset{\text { Rumah A ini memiliki luasan }}{\stackrel{5.2 \mathrm{~m}}{ }} \\
65,78 \mathrm{~m}^{2} \text {. Dikategorikan sebagai } \\
\text { rumah sederhana dikarenakan } \\
\text { luasannya di antara } 60 \mathrm{~m}^{2} \mathrm{~s} / \mathrm{d} 75 \mathrm{~m}^{2} .\end{array}$ & $\begin{array}{l}\text { - Pagar kolom } \\
\text { dan dinding } \\
\text { batu bata } \\
\text { - } \text { Besi hollow } \\
\text { - } \text { Polycarbonate } \\
\text { - Finishing cat } \\
\text { tembok dan } \\
\text { besi }\end{array}$ & $\begin{array}{l}\text { Rumah } \\
\text { memiliki } \\
\text { batasan yang } \\
\text { jelas dengan } \\
\text { dikelilingi } \\
\text { pagar masif dan } \\
\text { bukaan pagar } \\
\text { berupa besi } \\
\text { yang ditutup } \\
\text { dengan } \\
\text { polycarbonate. }\end{array}$ & $\begin{array}{l}\text { Pagar memiliki } \\
\text { ketinggian } 1 \mathrm{~m} .\end{array}$ & $\begin{array}{l}\text { Tidak terdapat } \\
\text { elemen } \\
\text { ornamen atau } \\
\text { material yang } \\
\text { menarik pada } \\
\text { pagar. }\end{array}$ \\
\hline $\begin{array}{l}\stackrel{2,4 \mathrm{~m}}{4,8 \mathrm{~m}} \\
\text { Rumah B ini memiliki luasan } \\
61,48 \mathrm{~m}^{2} \text {. Dikategorikan sebagai } \\
\text { rumah sederhana dikarenakan } \\
\text { luasannya di antara } 60 \mathrm{~m}^{2} \mathrm{~s} / \mathrm{d} 75 \mathrm{~m}^{2} \text {. }\end{array}$ & $\begin{array}{l}\text { - Pagar kolom } \\
\text { dan dinding } \\
\text { bata } \\
\text { - Besi hollow } \\
\text { - Besi ulir } \\
\text { - Finishing cat } \\
\text { tembok dan } \\
\text { besi }\end{array}$ & $\begin{array}{l}\text { Memiliki } \\
\text { batasan lahan } \\
\text { yang jelas } \\
\text { berupa } \\
\text { perpaduan } \\
\text { pagar dinding } \\
\text { masif dan pagar } \\
\text { besi. }\end{array}$ & $\begin{array}{l}\text { Pagar memiliki } \\
\text { ketinggian } 1 \mathrm{~m} .\end{array}$ & $\begin{array}{l}\text { Penggunaan } \\
\text { material baku } \\
\text { berupa dinding } \\
\text { batu bata, tidak } \\
\text { terdapat } \\
\text { material yang } \\
\text { menarik yang } \\
\text { mendukung } \\
\text { keindahan pada } \\
\text { pagar. }\end{array}$ \\
\hline
\end{tabular}


Jurnal PRAXIS | Vol. 2 | No. 1 | September 2019

\begin{tabular}{|c|c|c|c|c|}
\hline rumah sederhana dikarenakan & $\begin{array}{l}\text { - Pagar kolom } \\
\text { dan dinding } \\
\text { bata } \\
\text { - Besi hollow } \\
\text { - Besi ulir } \\
\text { - Finishing cat } \\
\text { tembok dan } \\
\text { besi }\end{array}$ & $\begin{array}{l}\text { Rumah } \\
\text { dikelilingi } \\
\text { batasan yang } \\
\text { jelas berupa } \\
\text { pagar dinding } \\
\text { masif dan pagar } \\
\text { besi. }\end{array}$ & $\begin{array}{l}\text { Pagar memiliki } \\
\text { ketinggian } \\
\text { kurang dari } 1 \mathrm{~m} \text {. }\end{array}$ & $\begin{array}{l}\text { Tidak ada } \\
\text { material yang } \\
\text { menonjol. } \\
\text { Hanya terdapat } \\
\text { ornament pada } \\
\text { pintu pagar. }\end{array}$ \\
\hline Hasil Peneliti: & an Sampel Ruma & Tinggal di Jalan ( & andi Intan IV & \\
\hline $\begin{array}{l}\stackrel{2 \mathrm{~m}}{5 \mathrm{~m}} \\
\stackrel{9.8 \mathrm{~m}}{\mathrm{rat}} \\
\text { rumah menengah dikarenakan } \\
\text { luasannya di antara } 80 \mathrm{~m}^{2} \mathrm{~s} / \mathrm{d} \\
200 \mathrm{~m}^{2} \text {. Dikategorikan sebagai }\end{array}$ & 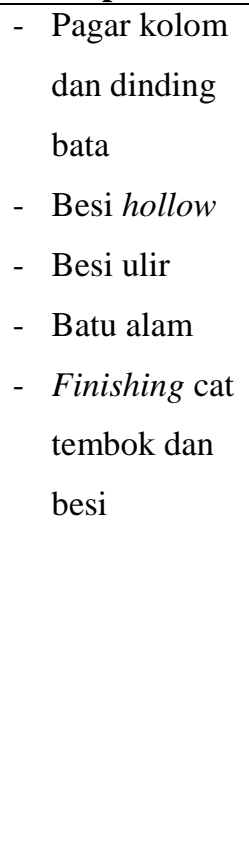 & $\begin{array}{l}\text { Batasan berupa } \\
\text { pagar dinding } \\
\text { masif } \\
\text { dipadukan } \\
\text { dengan pagar } \\
\text { besi. }\end{array}$ & $\begin{array}{l}\text { Pagar memiliki } \\
\text { ketinggian } 2 \mathrm{~m} .\end{array}$ & $\begin{array}{l}\text { Desain pagar } \\
\text { selaras dengan } \\
\text { gaya dari } \\
\text { rumah, modern } \\
\text { minimalis } \\
\text { dengan aksen } \\
\text { batu alam pada } \\
\text { beberapa } \\
\text { sisinya. }\end{array}$ \\
\hline
\end{tabular}


Jurnal PRAXIS | Vol. 2 | No. 1 | September 2019

\begin{tabular}{|c|c|c|c|c|}
\hline $\begin{array}{l}\text { Rumah B } \\
\text { Rumah B memiliki luas } 92,3 \mathrm{~m}^{2} \text {. } \\
\text { Dikategorikan sebagai rumah } \\
\text { sederhana dikarenakan luasannya } \\
\text { di antara } 60 \mathrm{~m}^{2} \text { s/d } 75 \mathrm{~m}^{2} \text {. }\end{array}$ & $\begin{array}{l}\text { - Pagar kolom } \\
\text { dan bata } \\
\text { - Besi hollow } \\
\text { - } \text { Besi ulir } \\
\text { - } \text { Finishing cat } \\
\text { tembok dan } \\
\text { besi. }\end{array}$ & $\begin{array}{l}\text { Memiliki } \\
\text { batasan lahan } \\
\text { yang jelas } \\
\text { berupa } \\
\text { perpaduan } \\
\text { pagar dinding } \\
\text { masif dan pagar } \\
\text { besi. }\end{array}$ & $\begin{array}{l}\text { Pagar memiliki } \\
\text { ketinggian di } \\
\text { atas } 1 \mathrm{~m} \text {. }\end{array}$ & $\begin{array}{l}\text { Penggunaan } \\
\text { material baku } \\
\text { pada dinding } \\
\text { pagar, terdapat } \\
\text { ornamen besi } \\
\text { ulir pada pintu } \\
\text { pagar. }\end{array}$ \\
\hline
\end{tabular}

\section{KESIMPULAN}

Setelah dilakukan observasi lapangan terdapat beragam karakter pagar pada kawasan permukiman Pasadena, tetapi walaupun memiliki keberagaman pada dasarnya pagar-pagar tersebut memiliki aspek-aspek fungsi yang sama berdasar klasifikasi tipe rumahnya.

1. Pada kawasan Perumahan Pasadena Semarang, rumahrumah yang ada rata-rata memiliki gaya modern minimalis. Dari gaya rumah tersebut tentunya mempengaruhi gaya pagar sebagai elemen kesatuan dari rumah itu sendiri.

2. Pada pembahasan telah dituliskan bahwa klasifikasi rumah tinggal digolongkan menjadi 3 (tiga) tipe rumah; rumah sederhana, rumah menengah, dan rumah mewah. Sampel dari tiap rumah tersebut juga sudah dijelaskan berdasar aspek - aspek fungsi yang ada dalam pagar, yaitu batas properti, pengaman dan sebagai elemen estetika. Pada tipe rumah mewah, karakteristik pagar dilihat dari fungsinya sebagai batas properti sangatlah jelas dan bahkan merupakan fungsi yang mutlak, tidak ada rumah dari tipe mewah yang tidak memiliki pagar. Kemudian 
dilihat dari ketinggian pagar, pada tipe rumah mewah tinggi pagar rata - rata mencapai $2 \mathrm{~m}$. Dibandingkan dengan tipe tipe rumah lain terutama tipe rumah sederhana, dapat dilihat bahwa tinggi pagar sangat berpengaruh pada aspek keamanan dari rumah itu sendiri. Kemudian dilihat dari aspek estetika, tipe rumah mewah sangat memperhatikan citra dari pagar rumahnya. Elemen estetika dapat dilihat dari ornamen - ornamen yang ditambahkan pada fasad dan tema dari desain pagar yang diterapkan selaras dengan tampilan keseluruhan dari rumah. Karakteristik pagar rumah pada tipe menengah dilihat dari fungsinya sebagai batas properti, sama halnya dengan tipe rumah mewah tipe rumah ini juga memiliki pagar dengan batasan yang jelas. Pada tipe ini juga memperhatikan fungsi pagar sebagai pengaman. Tipe rumah menengah memiliki ketinggian pagar $1,5 \mathrm{~m}-2 \mathrm{~m}$. Tipe rumah menengah juga memperhatikan citra dari pagar rumahnya dengan pemberian material yang menarik pada pagar. Pada tipe pagar rumah sederhana juga terdapat batasan yang jelas antara lahan satu dengan yang lainnya. Untuk pagar sebagai fungsi pengaman kurang diperhatikan dilihat dari ketinggian pagar yang rata rata mencapai $1 \mathrm{~m}$. Ketinggian pagar tersebut dibandingkan dengan tipe rumah lainnya dapat dikatakan terhitung rendah. Sedangkan pada elemen estetika, tipe pagar sederhana juga kurang memperhatikan estetika dari pagar rumahnya. Pagar terdiri dari material yang baku dan hanya mempertimbangkan fungsinya sebagai batas sebuah lahan saja. 


\section{DAFTAR PUSTAKA}

Akmal, I. (2017). Ide Rumah (edisi 12)

Bayu, I. (2008). Pagar Untuk Rumah Tinggal

Mahmud, D. (1990). Psikologi Pendidikan. FIP-IKIP. Yogyakarta: BPFE

Pass, C dan Bryan Lowes. (1994). Kamus Lengkap Ekonomi Edisi Kedua. Jakarta: Erlangga (Judul Asli: Dictionary of Economics, Harper Collins Publishing Ltd. 1988)

Singarimbun, M. (1985). Metode Penelitian Survey. Jakarta: PT. Pustaka LP3ES Indonesia

Soekanto, S. (2007). Sosiologi Suatu Pengantar. Jakarta: PT. Raja Grafindo Persada
Sumardi, M dan Hans Dieter-Evers. (1982). Kemiskinan dan Kebutuhan Pokok. Jakarta: Rajawali

Suparno, S M. (2007). Perencanaan dan Pengembangan Perumahan. Yogyakarta: Andi Offset

Usman, S. (2004). Pembangunan dan Pemberdayaan Masyarakat. Yogyarta: Pustaka Pelajar

htpps://kbbi.web.id/pagar

https://pixabay.com/id/photos/kayu-pagarpagar-kayu-3160743/ 